\title{
PERFIL DOS GRADUANDOS DO PRIMEIRO PERÍODO EM MEDICINA VETERINÁRIA DA FACULDADE DE CIÊNCIAS AGRÁRIAS E VETERINÁRIAS - UNESP, CÂMPUS JABOTICABAL E SUA RELAÇÃO COM OS ANIMAIS DOMÉSTICOS
}

\author{
FIRST GRADE STUDENTS PROFILE OF VETERINARY MEDICINE OF THE \\ COLLEGE UNESP CAMPI JABOTICABAL AND THEIR RELATION WITH THE \\ DOMESTIC ANIMALS
}

J. H. BEGALI ${ }^{1}$, C. R. BASTOS ${ }^{1}$, M. A. PICINATO ${ }^{1}$, A. P. R. GRISÓLIO ${ }^{1}$, P. E. CARRARO ${ }^{1}$, F. O. BARBOSA ${ }^{1}$, A. A. B. CARVALHO ${ }^{2}$

\begin{abstract}
RESUMO
A medicina veterinária é uma profissão abrangente, fundamental para o desenvolvimento agropecuário, para a melhoria da saúde dos animais e saúde das pessoas. O graduando de medicina veterinária deve conhecer as múltiplas áreas que compõe o campo de trabalho da sua profissão, além da atuação nos diversos setores. Com o objetivo de traçar o perfil dos graduandos do primeiro período de medicina veterinária da UNESP, Câmpus Jaboticabal foi elaborado um questionário a 38 alunos ingressantes na universidade sobre as áreas de maior interesse, a grade horária e disciplinas do curso, e sobre o convívio com os animais domésticos. Dos 38 alunos,92\% afirmaram que ingressaram no curso por preferência pessoal e por afinidade aos animais.Das áreas de maior interesse, $92 \%$ citaram clínica e cirurgia de animais; 39\%, pesquisa científica; 32\%, manejo e conservação de espécies; $29 \%$, saúde pública veterinária, e 16\%, outras áreas. Além disso, $63 \%$ dos participantes afirmaram estarem satisfeitos com a grade horária e as disciplinas. Com relação ao convívio com os animais domésticos, $89 \%$ disseram possuir animais em casa ou república, $71 \%$ afirmaram conviver com os animais dentro de casa, e $32 \%$ afirmaram que dormem com algum animal de estimação( $83 \%$ cães e $17 \%$ gatos). Ainda,58\% afirmaram se preocupar com a saúde do seu animal e $42 \%$ se preocupam com a saúde do animal e com a possibilidade que ele transmita alguma doença para a família. Com o perfil dos estudantes traçados, é possível identificar as características e carências dos futuros profissionais, além de caracterizar as necessidades e planejar atividades que promovam o desenvolvimento do aluno. $\mathrm{O}$ resultado obtido demonstrou um perfil voltado para clínica e cirurgia de animais e uma intensa relação com animais domésticos. Torna-se necessário que a educação em medicina veterinária seja bem distribuída, contemplando todas as áreas, estimulando o pensamento interdisciplinar e o envolvimento dos alunos.
\end{abstract}

PALAVRAS-CHAVE: ANIMAIS DOMÉSTICOS. MÉDICINA VETERINÁRIA. PERFIL PROFISSIONAL.

AGRADECIMENTOS: CAPES

ÁREA TEMÁTICA: SAÚDE PÚBLICA 